\title{
Relationship of physiological plant functional traits with soil carbon stock in the temperate forest of Garhwal Himalaya
}

\author{
Amit Kumar*, Parmanand Kumar, Hukum Singh, Sarita Bisht and \\ Narendra Kumar \\ Forest Ecology and Climate Change Division, Forest Research Institute, Dehradun 248 006, India
}

\begin{abstract}
The composition of species can play an essential role in reducing the atmospheric carbon dioxide. Forest trees are an important part of the functioning of the terrestrial ecosystem, predominantly in the cycling of carbon. However, tree physiology is much less studied than crop physiology for several reasons: a large number of species, difficulty in measuring photosynthesis of tall trees or forest species. This study aims to establish the relationship between physiological plant functional traits (photosynthesis rate, transpiration rate, stomatal conductance, leaf chlorophyll and carotenoid content) with soil carbon stock in Pinus roxburghii forest of Garhwal Himalaya. The present findings revealed that photosynthesis rate, chlorophyll $a$, chlorophyll $b$ and carotenoid content positively correlated to the soil carbon stock. The different regression models also showed that photosynthesis rate with water-use efficiency, stomatal conductance and carotenoid content is a good predictor of soil carbon stock in Pinus roxburghii forest. Physiological plant functional characteristics are thus crucial for regulating the carbon cycle and ecosystem functioning in Garhwal Himalaya.
\end{abstract}

Keywords: Carbon assimilation, ecosystem services, soil carbon, water-use efficiency.

THROUGH the impact of the dominant (locally most abundant) plant functional trait on $\mathrm{C}$ dynamics, functional diversity influences $\mathrm{C}$ storage in standing vegetation, litter and soil through the impact of the dominant (most abundant) plant functional traits ${ }^{1}$. Plant communities with taller and denser stems accumulate more $\mathrm{C}$ in standing biomass, leading to significant storage of $\mathrm{C}$ in the soil due to higher $C$ input and a longer $C$ residence period ${ }^{2}$. The existence of diverging functional trait values affects $\mathrm{C}$ dynamics and involves $\mathrm{C}$ accumulation in plant and soil stocks. The coexistence of plants with contrasting functional trait values can contribute to more efficient use of resources by the population, resulting in increased biomass production and $\mathrm{C}$ input into the soil and increased above-ground and soil $\mathrm{C}$ stocks ${ }^{3}$. More than two-thirds of

\footnotetext{
*For correspondence. (e-mail: amitudu@gmail.com)
}

organic $\mathrm{C}$ stored in terrestrial ecosystems is stored in organic soils ${ }^{4}$. C in forest soil is vulnerable to losses under the current climate system, with consequences for soil biodiversity, productivity and climate feedback ${ }^{5}$. As soil $\mathrm{C}$ sequestration is an important ecosystem service linked to climate change mitigation, a better understanding of the underlying processes and mechanisms is needed. In this context, determining the impact of plant functional traits (such as leaf and physiological traits) on $\mathrm{C}$ decomposition and soil stabilization has become a major environmental challenge ${ }^{6}$. A biologically diverse temperate forest retains 50 times more carbon than a monoculture plantation per unit of area. As a result, forest trees play an important role in the functioning of the terrestrial ecosystem, especially in the carbon cycle ${ }^{7}$.

On the other hand, tree physiology has received significant attention from crop photosynthesis for a variety of reasons, including the vast number of organisms and the difficulty of calculating photosynthesis of whole trees or forest stands ${ }^{8}$. Biological diversity has the potential to contribute significantly to the reduction of greenhouse gas emissions in the atmosphere. The use of native tree species is a reliable tool for forest regeneration and reforestation $^{9}$. Trees that are suitable for clean development mechanism (CDM) should have the following three characteristics: (i) seedlings that can be easily adapted to open areas after planting from shades (nutrients) to sunlight conditions; (ii) fast-growing species that are capable of competing with weeds and ferns ${ }^{10}$; (iii) tree species with a high $\mathrm{CO}_{2}$ assimilation capacity and a long life span. However, these physiological characteristics vary widely between species of trees. In temperate climate zones, natural forests have a higher $\mathrm{CO}_{2}$ assimilation rate, implying that $\mathrm{CO}_{2}$ assimilation rate can assess carbon removal efficiency from the atmosphere and fix it in the form of carbon stock ${ }^{11}$.

In this study, physiological traits of trees concerning soil carbon stock (SOC) in temperate forest ecosystems were examined. This study is aimed to provide information on tree characteristics related to high carbon sequestration by developing the relationship between physiological traits and SOC. 


\section{Materials and methods}

\section{Site description}

The study was carried out in the Kempty watershed of Garhwal Himalaya, India, from 2018 to 2020. The watershed is situated between $30^{\circ} 28.01-3^{\circ} 28.54^{\prime} \mathrm{N}$, $78^{\circ} 1.50-78^{\circ} 2.30^{\prime} \mathrm{E}$, with an average elevation of $1662 \mathrm{~m}$ and average slope $5.5 \%$. It is located in the middle part of the Indian Himalaya with an area 870 ha. The selected forests come under the Himalayan moist temperate forest. The watershed is comprised of two types of forests, i.e. Pinus roxburghii and Quercus leucotrichophora. In addition, the forest consists of some other scattered tree species, i.e. Quercus leucotrichophora, Quercus floribunda, Pinus roxburghii, Pinus wallichiana, Daphniphyllum himalayense, Toona serrate, Acer oblongum, Pyrus pashia, Cornus macrophylla and Myrica esculenta. Thus, in the present study, we focused on Pinus roxburghii forest (PF) because this forest was approachable as compared to other forest tree species.

\section{Field sampling}

We randomly selected the five healthy and matured tree species to measure the physiological plant functional traits. For the measurement of all physiological plant functional traits, the canopy of tree chosen species was stratified into three strata, i.e. lower, middle and upper part of the canopy from bottom to top. Then each stratum is further divided into four directions. A total of twelve (three strata and four directions) measurements were taken from a tree. The flat-topped bifurcated aluminium ladder was used to reach all the strata and directions to measure all parameters.

\section{Measurement of physiological traits}

The physiological traits were measured in a natural condition (intact leaf to the canopy) with the help of a ladder at the seasonal interval (rainy, winter and summer). Five healthy trees were selected for the measurement of these traits. The physiological traits were measured in fully expanded leaves using an infrared gas analyzer (IRGA) (portable photosynthesis system Li-COR $6400 \mathrm{XT}$, Lincoln NE, USA instrument). The IRGA directly measures the delta $\mathrm{CO}_{2}$ and delta $\mathrm{H}_{2} \mathrm{O}$, leaf temperature, light intensity in the chamber and gas flux; while the following were indirectly measured, based on the algorithms, by the software of system; internal $\mathrm{CO}_{2}$ concentration $(\mathrm{Ci}-$ $\mu \mathrm{mol} \mathrm{CO} \mathrm{Cm}^{-2} \mathrm{~s}^{-1}$ ), transpiration $\left(\mathrm{E}-\mathrm{mmol} \mathrm{H}_{2} \mathrm{O} \mathrm{m} \mathrm{m}^{-2} \mathrm{~s}^{-1}\right.$ ), stomatal conductance $\left(\mathrm{Gs}-\mathrm{mol} \mathrm{H}_{2} \mathrm{O} \mathrm{m}^{-2} \mathrm{~s}^{-1}\right), \mathrm{CO}_{2}$ assimilation rate $\left(\mathrm{A}-\mu \mathrm{mol} \mathrm{CO} \mathrm{CO}_{2} \mathrm{~m}^{-2} \mathrm{~s}^{-1}\right)$ and water-use efficiency (WUE; $\mathrm{A} / \mathrm{E}-\mu \mathrm{mol} \mathrm{CO} \mathrm{Col}^{-1} \mathrm{H}_{2} \mathrm{O}$ ).

\section{Estimation of soil carbon stock}

SOC is determined by

$$
\begin{gathered}
\mathrm{C} \text { stock }=\sum n i=p i \times \mathrm{SOC} i \times \mathrm{BD} i \times(1-\mathrm{CP} i) \\
\left(\text { in } \mathrm{kg} \mathrm{m}^{-2}\right),
\end{gathered}
$$

where $p i$ is the thickness of the soil layer $i$ in $\mathrm{m}$; $\mathrm{SOC} i$ is the organic carbon concentration of layer $i$ in fine soil in $\mathrm{g} \mathrm{kg}^{-1} ; \mathrm{BD} i$ is the bulk density of layer $i$ of fine soil in $\mathrm{kg} \mathrm{dm}^{-3} ; \mathrm{CP} i$ is the percentage of coarse particles of layer $i . n$ is the number of soil layers.

\section{Soil carbon stock models}

In order to identify the most important traits affecting the SOC, a predictive statistical analysis was performed. The physiological plant functional traits, i.e. photosynthesis rate, transpiration rate, stomatal conductance, chlorophyll and carotenoid content were correlated with SOC to understand the relationship. The regression models were also developed for SOC with the help of the multiple regression method.

\section{Statistical analysis}

The relationship between physiological plant functional traits with SOC was evaluated by the correlation matrix followed by developing the regression models. The best model was selected based on $R^{2}$, AIC (Akaike's information criterion) and BIC (Bayesian information criterion) criteria

$$
\mathrm{AIC}=n \times \log \left(\sigma^{2}\right)+2 \times K,(10),
$$

where $\sigma^{2}=$ (residual sum of squares) $/ n, n$ the sample size and $K$ is the number of estimated parameter where variance was also counted as an estimated parameter

$$
\mathrm{BIC}=-2 \times \mathrm{LL}+\log (N) \times k,
$$

where $\log ()$ has the base-e called the natural logarithm, LL the log-likelihood of the model, $N$ the number of examples in the training dataset and $k$ the number of parameters in the model. The models were developed by using $R$ statistical studio software (4.0.2 version).

\section{Results}

Correlation between physiological traits and carbon stock

The correlation between physiological plant functional traits and soil carbon sequestration under pine forest $(\mathrm{PF})$ 
Table 1. Comparison of statistical parameters for developed regression models

\begin{tabular}{|c|c|c|c|c|c|c|}
\hline Regression models & SE & $F$-value & $P$-value & $R^{2}$ & $\mathrm{AIC}$ & $\mathrm{BIC}$ \\
\hline $\mathrm{SOC}=2.77 \mathrm{~A}-2.98 \mathrm{WUE}+67.19$ & 9.16 & 8.52 & $<0.002$ & 0.45 & 179.20 & 183.92 \\
\hline $\mathrm{SOC}=6.74 \mathrm{~A}-126.65 \mathrm{Gs}+70.26$ & 10.51 & 4.47 & $<0.02$ & 0.30 & 185.81 & 190.53 \\
\hline $\mathrm{SOC}=5.04 \mathrm{E}+4.10 \mathrm{WUE}+55.83$ & 9.56 & 6.94 & $<0.005$ & 0.40 & 181.28 & 185.99 \\
\hline $\mathrm{SOC}=2.90 \mathrm{~A}-10.88 \mathrm{CTN}+83.06$ & 10.42 & 4.74 & $<0.02$ & 0.31 & 185.39 & 190.10 \\
\hline
\end{tabular}

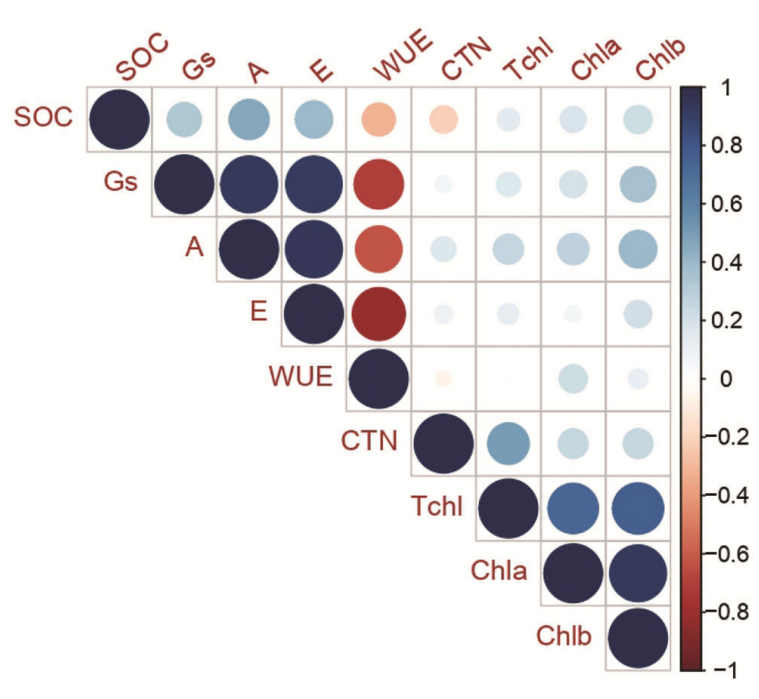

Figure 1. Correlation analysis between physiological plant functional traits and soil organic carbon stock under pine forest.

is shown in Figure 1, this showed that photosynthesis rate (A) is significantly positive $(r=0.93, \quad P<0.0002$, $s e=0.07)$ correlated to stomatal conductance (GS), transpiration rate (E) $(r=0.94, P<0.0006, s e=0.07)$ and significantly negative correlated with WUE $(r=$ $-0.62, P<0.001$, se=0.16). However, this is nonsignificantly positive correlated to SOC stock $(r=0.47$, $P<0.002$, se $=0.18)$. GS is significantly positive correlated to $\mathrm{E}(r=0.93, P<0.0001$, se $=0.08)$, and WUE $(r=-0.70, P<0.001$, se $=0.15)$ significantly negative correlated to GS. In contrast, non-significantly positive correlated to SOC $(r=0.34, P<0.01$, se $=0.20)$. E is significantly negative correlated with WUE $(r=-0.81$, $P<0.001$, se $=0.12)$ whereas non-significantly positive correlated to SOC $(r=0.40, P<0.004$, se $=0.19)$. WUE is non-significantly negative correlated with SOC $(r=$ $-0.32, P<0.01$, se $=0.20)$. Chlorophyll $a(\mathrm{Chl} a)$ is significantly positive correlated to chlorophyll $b(\mathrm{Chl} b)$ ( $r=0.94, P<0.0002$, se $=0.07)$, (total chlorophyll) Tchl $(r=0.74, P<0.0004$, se $=0.14)$ and non-significantly positive correlated to SOC $(r=0.19, P<0.03$, se $=0.20)$. $\mathrm{Chl} b$ is significantly positive correlated to Tchl $(r=0.76$, $P<0.001$, se $=0.13$ ) and non-significantly positive correlated to $\operatorname{SOC}(r=0.23, P<0.02$, se $=0.20)$. Tch1 is significantly positive correlated to carotenoid (CTN) $(r=0.50, P<0.01, s e=0.18)$ and non-significantly positive correlated to $\operatorname{SOC}(r=0.15, P<0.49$, se $=0.21)$.
CTN non-significantly negative correlated to SOC $(r=$ $-0.22, P<0.30$, se $=0.20)$.

\section{Regression models for carbon stock}

The regression model for physiological traits of oak forest was also found to be significant $(F=8.52, P<00.2)$. The $R^{2}$ among $\mathrm{A}, \mathrm{WUE}$ and SOC was 0.45 . However, AIC and BIC were good as 179.20 and 183.92 respectively. This model shows that photosynthesis rate (A) together with WUE was a strong predictor (Table 1, Figure 2) of soil carbon sequestration relative to the other regression model that we tried to test.

The linear relationship between photosynthesis rate, stomatal conductance and soil carbon sequestration was developed by the regression model (Table 1, Figure 3) and found to be significant $(F=4.47, P<0.02)$. The coefficient of determination $R^{2}$ for this regression model was 0.30. The AIC (185.81) and BIC (190.53) of the regression model show the adaptability of the model. Hence, the photosynthesis rate with stomatal conductance in a pine forest is a good predictor for soil carbon sequestration.

Table 1 and Figure 4 show that the regression model among transpiration rate, WUE and soil carbon sequestration of pine forest is significant $(F=6.94, P<0.005)$. The statistical parameters used to compare regressions such as $R^{2}$, AIC and BIC were 0.40, 181.28 and 185.99 respectively for the regression model developed among transpiration rate, WUE and soil carbon sequestration of the pine forest. Thus, as shown by the results, transpiration rate along with WUE will accumulate more carbon in the soil.

The regression model among photosynthesis rate, carotenoid content and SOC of pine forest is presented in Table 1 and Figure 5 depicts that it was significant $(F=4.74, P<0.02)$. The $R^{2}$ for this model was 0.31 . The model represents the least AIC (185.39) and BIC (190.10) values among the tested model. The model suggests that photosynthesis rate with carotenoid content is a good predictor for soil carbon sequestration.

\section{Discussion}

We showed the relationship between different physiological plant functional traits and SOC in the selected 
forest. We found that among the physiological traits, photosynthesis rate, transpiration rate, chlorophyll $a$, chlorophyll $b$, total chlorophyll and carotenoid are good predictors for SOC and sequestration. It might be due to the higher carbon assimilation and fixation of $\mathrm{CO}_{2}$ molecules from the atmosphere through Pinus roxburghii forest. The carbon from $\mathrm{CO}_{2}$ is stored in wood and becomes part of the plant ${ }^{12}$. Subsequently, the carbon is released into the environment when the plant or tree dies ${ }^{13}$. However, this is not the only path that carbon will carry back into the atmosphere. For certain cases, net photosynthesis has been found in many instances to be

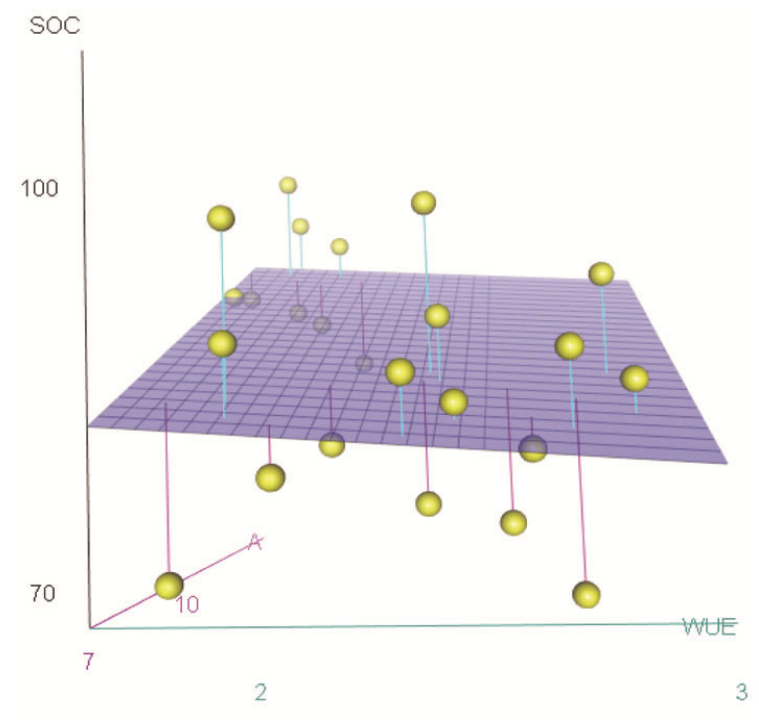

Figure 2. Three-dimensional scattered regression models among $\mathrm{CO}_{2}$ assimilation rate, water use efficiency and soil organic carbon under pine forest $(\mathrm{PF})$

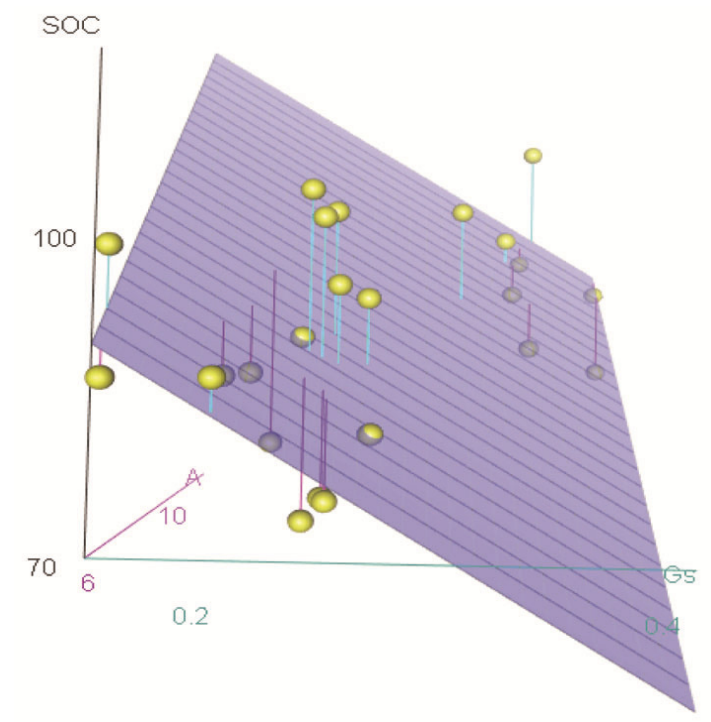

Figure 3. Three-dimensional scattered regression models among $\mathrm{CO}_{2}$ assimilation rate, stomatal conductance and soil organic carbon under pine forest. poorly associated with growth rate, i.e. difference in leaf area, carbon partitioning pattern, and variance in wood and root respiration rate ${ }^{14}$. Harvestable product of trees (the stem) depends not only on the photosynthetic carbon uptake of the foliage, but also on the respiration of the different organs and the expenditure of carbon into renewable organs (leaves, fine roots) and non-harvestable organs (branches and large roots) ${ }^{15}$. Consequently, there is an apparent connection between photosynthesis and the production of biomass ${ }^{16}$. However, a fast-growing tree demands additional photosynthesis, but the opposite is not necessarily true ${ }^{17}$.

Plants are the primary source of organic carbon in the soil, either from the decomposition of aerial plant parts or

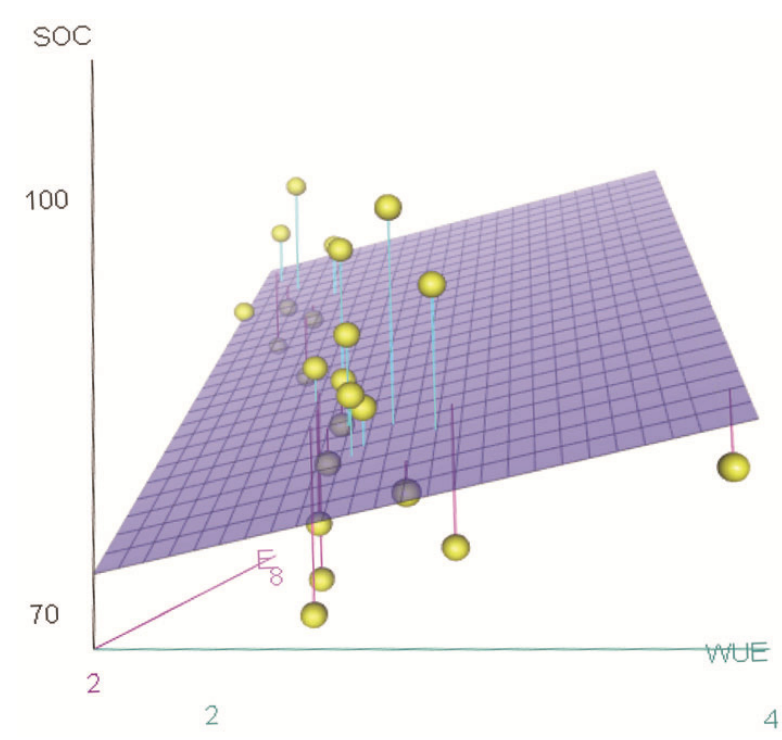

Figure 4. Three-dimensional scattered regression models among transpiration rate, water use efficiency and soil organic carbon under pine forest.

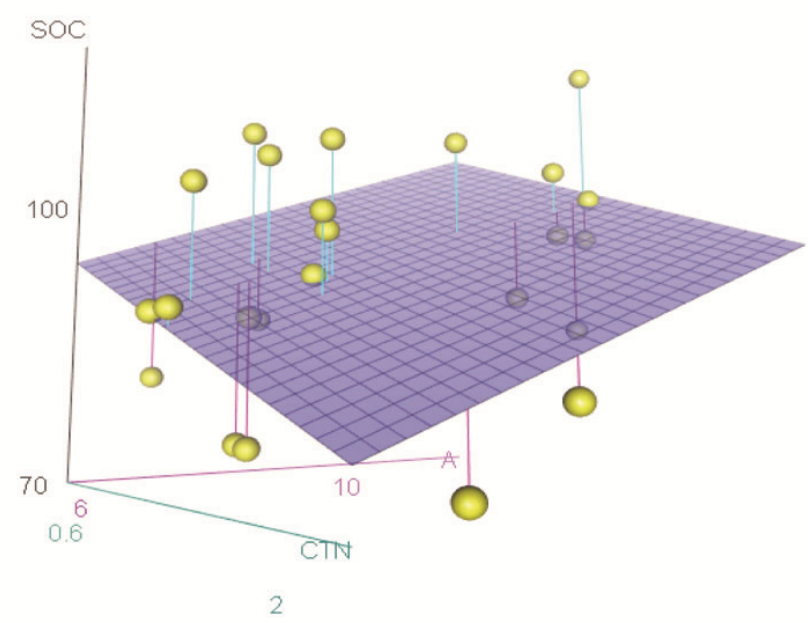

Figure 5. Three-dimensional scattered regression models among $\mathrm{CO}_{2}$ assimilation rate, carotenoid and soil organic carbon under pine forest. 


\section{RESEARCH ARTICLES}

from underground parts of plants such as roots in the form of root casualty, root exudates and root respira$\operatorname{tion}^{18}$. Approximately $40 \%$ of the photosynthates synthesized in the plant components lost to the rhizosphere via the root system. The rate of loss is affected by many factors, such as plant age, various biotic and abiotic stresses, etc. ${ }^{19}$. Consequent rises in atmospheric $\mathrm{CO}_{2}$ and global temperatures may have several different implications for soil carbon inputs through photosynthetic controls and carbon losses through respiration and decomposition ${ }^{20}$. The high responsiveness of leaf transpiration, net photosynthetic rate and stomatal behaviour verified obstruction of plant growth under different environmental condition $^{21}$. Previous studies have shown that adverse climatic conditions inhibit photosynthesis rate due to stomatal and non-stomatal causes, leading to a decline in carbon sequestration $^{22}$. Increased temperatures can also affect the carbon balance by limiting water availability and reducing the photosynthesis rate ${ }^{23}$.

In general, strong radiation and extreme temperatures decrease the photosynthetic rate by declining the stomatal conductivity, depressing the RuBP carboxylase activity, damaging the photosynthetic rate and enhancing the respiration rate $^{24}$. It was noted that low-temperature native plants with abundant soil moisture habitats usually had an optimum photosynthetic rate. Therefore, with increased photosynthesis and lower water loss, the water efficiency of plants is increased. Thus, it seems that more carbon dioxide in the atmosphere is good for plants that grow faster and use less water and more carbon sequestration ${ }^{25}$. Chlorophyll is a chemical substance absorbing and transferring energy from sunlight to high-energy electrons ${ }^{26}$. It occurs during light photosynthesis reactions, while highenergy electrons are subsequently used to synthesize sugar glucose during dark reactions ${ }^{27}$. Pigments other than chlorophyll are carotenoids which also play an important role in photosynthetic reactions ${ }^{28}$. Chlorophyll, carotenoid and other light-sensitive pigments that absorb solar energy are found in photosynthetic cells. Such cells can transform solar energy into energy-rich organic molecules such as glucose in the presence of carbon dioxide ${ }^{29}$. These cells not only drive the global carbon cycle, but they also produce much of the oxygen present in the atmosphere of the earth ${ }^{30}$. Hence, these photosynthetic pigments also regulate the carbon stock and sequestration by influencing the rate of photosynthesis.

\section{Conclusion}

Species composition can play an essential role in reducing the atmospheric build-up of carbon dioxide. Forest trees form a necessary part of the terrestrial ecosystem's functioning, particularly in the carbon cycle. The $\mathrm{CO}_{2}$ assimilated by the plants through several other traits like chlorophyll and carotenoid fixed in the plant biomass and via litterfall fixes the soil's carbon. Hence, it may be concluded from the present study that physiological traits are a good predictor for SOC. This study confirmed that Pinus roxburghii forests in the Indian Himalayas worked better to reduce $\mathrm{CO}_{2}$ emissions by fixing carbon in the soil through a physiological plant mechanism.

1. Kumar, A. et al., Carbon mineralization and inorganic nitrogen pools under Terminalia chebula Retz. - based agroforestry system in Himalayan Foothills, India. Forest Sci., 2020. 66(5), 634-643.

2. Kumar, A. et al., Soil organic carbon pools under Terminalia chebula Retz. based agroforestry system in Himalayan foothills, India. Curr. Sci., 2020, 118(7), 1098-1103.

3. Kumar, M., Rawat, S. P. S., Singh, H., Ravindranath, N. H. and Kalra, N., Dynamic forest vegetation models for predicting impacts of climate change on forests: an Indian perspective. Indian J. For., 2018, 41(1), 1-12.

4. Sharma, R., Chauhan, S. K. and Tripathi, A. M., Carbon sequestration potential in agroforestry system in India: an analysis for carbon project. Agrofor. Syst., 2016, 90(4), 631-644.

5. deDeyn, G. D. B., Cornelissen, J. H. C. and Bardgett, R. D., Plant functional traits and soil carbon sequestration in contrasting biomes. Ecol. Lett., 2008, 11, 516-531.

6. Diaz, S., Lavorel, S., de Bello, F., Quetier, F., Grigulis, K. and Robson, T. M., Incorporating plant functional diversity effects in ecosystem service assessments. Proc. Natl. Acad. Sci., 2007, 104(52), 20684-20689.

7. Rawat, M., Arunachalam, K., Arunachalam, A., Alatalo, J. and Pandey, R., Associations of plant functional diversity with carbon accumulation in a temperate forest ecosystem in the Indian Himalayas. Ecol. Indic., 2019, 1(98), 861-868.

8. Hassiotou, F., Renton, M., Ludwig, M., Evans, J. R. and Veneklaas, E. J., Photosynthesis at an extreme end of the leaf trait spectrum: how does it relate to high leaf dry mass per area and associated structural parameters? J. Exp. Bot., 2010, 61(11), 30153028.

9. Kasel, S. and Bennett, L. T., Land-use history, forest conversion, and soil organic carbon in pine plantations and native forests of south eastern Australia. Geoderma, 2007, 137, 401-413.

10. Kim, D. G., Kirschbaum, M. U. and Beedy, T. L., Carbon sequestration and net emissions of $\mathrm{CH}_{4}$ and $\mathrm{N}_{2} \mathrm{O}$ under agroforestry: Synthesizing available data and suggestions for future studies. Agric. Ecosyst. Environ., 2016, 226, 65-78.

11. Kumar, A., Kumar, P., Singh, H. and Kumar, N., Adaptation and mitigation potential of roadside trees with bio-extraction of heavy metals under vehicular emissions and their impact on physiological traits during seasonal regimes. Urban For. Urban Green., 2020, 126900 .

12. Kirschbaum, M. U. F. and Tompkins, D., Photosynthetic responses to phosphorus nutrition in Eucalyptus grandis seedlings. Austr. J. Plant Physiol., 1990, 17, 527-535.

13. Singh, H., Yadav, M., Kumar, N., Kumar, A. and Kumar, M., Assessing adaptation and mitigation potential of roadside trees under the influence of vehicular emissions: A case study of Grevillea robusta and Mangifera indica planted in an urban city of India. PLoS ONE, 2020, 15(1), 557-562.

14. Ballantyne, A. P., Alden, C. B., Miller, J. B., Tans, P. P. and White, J. W. C., Increase in observed net carbon dioxide uptake by land and oceans during the past 50 years. Nature, 2012, 488, $70-72$.

15. King, D. A., Davies, S. J., Nur Supardi, N. M. and Tan, S., Tree growth is related to light interception and woody density in two mixed dipterocarp forests of Malaysia. Funct. Ecol., 2005, 19, $445-453$. 
16. Kitajima, K., Mulkey, S. S. and Wright, S. J., Decline of photosynthetic capacity with leaf age in relation to leaf longevities for five tropical canopy tree species. Am. J. Bot., 1997, 84, 702-708.

17. Casals, P., Romero, J., Rusch, G. and Ibrahim, M., Soil organic C and nutrient contents under trees with different functional characteristics in seasonally dry tropical silvopastures. Plant Soil, 2014, 374, 643-659.

18. Kumar, M., Rawat, S. P. S., Singh, H., Ravindranath, N. H. and Kalra, N., Dynamic forest vegetation models for predicting impacts of climate change on forests: An Indian perspective. Indian J. For., 2018, 41(1), 1-12.

19. Saidy, A. R., Smernik, R. J., Baldock, J. A., Kaiser, K. and Sanderman, J., Microbial degradation of organic carbon sorbed to phyllosilicate clays with and without hydrous iron oxide coating. Eur. J. Soil Sci., 2015, 66, 83-94.

20. Von Lutzow, M., Kögel-Knabner, I., Ekschmitt, K., Matzner, E., Guggenberger, G., Marschner, B. and Flessa, H., Stabilization of organic matter in temperate soils: mechanisms and their relevance under different soil conditions - a review. Eur. J. Soil Sci., 2006, 57, 426-445.

21. Lloyd, J. and Farquhar, G. D., Effects of rising temperatures and $\mathrm{CO}_{2}$ on the physiology of tropical forest trees. Philos. Trans. R. Soc. B: Biol. Sci., 2008, 27, 363(1498).

22. Andrade, H., Brook, R. and Ibrahim, M., Growth, production and carbon sequestration of silvopastoral systems with native timber species in the dry lowlands of Costa Rica. Plant Soil, 2008, 308 11-22.

23. Rennenberg, H., Loreto, F., Polle, A., Brilli, F., Fares, S., Beniwal, R. S. and Gessler, A. J., Physiological responses of forest trees to heat and drought. Plant Biol., 2006, 8(5), 556-571.

24. Jia, L., Liu, Z., Chen, W., Ye, Y., Yu, S. and He, X., Hormesis effects induced by cadmium on growth and photosynthetic per- formance in a hyperaccumulator, Lonicera japonica Thunb. J. Plant Growth Regulat., 2015, 34(1), 13-21.

25. Kallarackal, J. and Roby, T. J., Responses of trees to elevated carbon dioxide and climate change. Biodivers. Conserv., 2012, 21(5), 1327-1342.

26. Singh, H., Yadav, M., Kumar, N., Kumar, A. and Kumar, M., Assessing adaptation and mitigation potential of roadside trees under the influence of vehicular emissions: a case study of Grevillea robusta and Mangifera indica planted in an urban city of India. PLoS ONE, 2020, 15(1), 557-562.

27. Ballantyne, A. P., Alden, C. B., Miller, J. B., Tans, P. P. and White, J. W. C., Increase in observed net carbon dioxide uptake by land and oceans during the past 50 years. Nature, 2012, 488, 7072 .

28. Sharma, R., Singh, H., Kaushik, M., Nautiyal, R. and Singh, O., Adaptive physiological response, carbon partitioning, and biomass production of Withania somnifera (L.) Dunal grown under elevated $\mathrm{CO}_{2}$ regimes. 3 Biotech, 2018, 8(6), 1-10.

29. Vesterdal, L., Clarke, N., Sigurdsson, B. D. and Gundersen, P., Do tree species influence soil carbon stocks in temperate and boreal forests? For Ecol. Manage., 2013, 309, 4-18.

30. DaCosta, M. V. J., Morphological, physiological, biochemical and molecular response of rice seedlings to metallo-nanoparticles, Doctoral dissertation, Goa University, 2016.

Received 9 February 2021; accepted 23 February 2021

doi: $10.18520 / \mathrm{cs} / \mathrm{v} 120 / \mathrm{i} / 1368-1373$ 